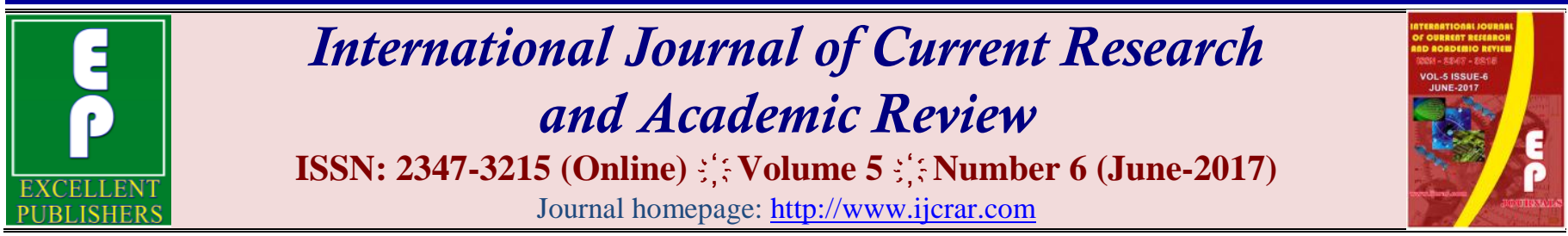

doi: https://doi.org/10.20546/ijcrar.2017.506.002

\title{
Production of Antibacterial and Larvicidal Extracellular Polysaccharide from Pseudomonas aeruginosa Strain b01 Isolated from Wastewater
}

\author{
N. Benit and A. Stella Roslin* \\ Department of Botany, Holy Cross College, Nagercoil, Kanyakumari District, Tamilnadu 629 001, India \\ *Corresponding author
}

\begin{abstract}
The aim of this study is to optimize extracellular polysaccharide (EPS) production from Pseudomonas aeruginosa B01 with potent antibacterial and larvicidal activity. EPS producing $P$. aeruginosa $\mathrm{B} 01$ was isolated from wastewater. Process parameters were optimized to enhance the production of EPS. EPS was fractionated with two-, three-volume of various solvent and antibacterial and larvicidal activities were evaluated. The bacterial cell growth was maximum after $48 \mathrm{~h}$ fermentation period, however, EPS production was maximum after $72 \mathrm{~h}$. EPS production was found to be high when this organism was grown in the medium containing $1 \%$ maltose, $1 \%$ ammonium sulphate and $0.1 \% \mathrm{Mn}^{2+}$ ions. EPS production was maximum at $\mathrm{pH} 7.5$ and at $30{ }^{\circ} \mathrm{C}$. Ethanol precipitated fractions showed high activity than other tested solvents. It was further subjected to Thin Layer Chromatography. EPS showed potent larvicidal activity against mosquito larva and showed potent activity against various pathogenic bacteria.
\end{abstract}

\section{Article Info}

Accepted: 05 June 2017

Available Online: 20 June 2017

\section{Keywords}

Pseudomonas aeruginosa, Extracellular polysaccharide, Optimization,

Antibacterial,

Larvicidal.

\section{Introduction}

Extracellular polysaccharides (EPSs) are a mixture of organic compounds that are released into the surrounding medium by microorganisms. These EPSs are considered as eco-friendly, cost effective and sustainable alternate to substitute the currently using chemical flocculants. These form a protective layer for the cells against the harsh environment such as salinity, temperature, $\mathrm{pH}$, heavy metals, UV radiation, biocides and heavy metals and also serve as carbon and energy reserves during starvation (Flemming and Wingender, 2010). EPSs contain humic substance, uronic acid and deoxyribonucleic acids, however, information about their concentration are highly limited (Tsuneda et al., 2001). The majority of bacterial isolates secrete EPS and these mucoid type polysaccharides generally have very high molecular weight (Sutherland, 1977). These EPSs may either be attached to the surface of the cell in the form of capsular polysaccharides or completely separated from the cell in the form of exopolysaccharides. Bacterial polysaccharide species represent a diverse range of macromolecules that include peptidoglycan and EPS. The structure and the function of these polysaccharides varied widely (Sutherland, 1985).

Biofilm formation is believed play significant role in protection toward antimicrobial agents and infection immunity. The organisms such as, Staphylococcus epidermidis and $P$. aeruginosa are most prevalent pathogens involved in clinical chronic infections. The growth of these bacteria within a biofilm provides them a 
host defense mechanism and protection from antibiotics by preventing penetration or by slowing down of different agents through the biofilm. The bacteria from the genera including, Escherichia, Legionella, Streptococcus and Vibrio also produced biofilm ( $\mathrm{Vu}$ et al., 2009). EPSs have revolutionized the medical sectors and industrial due to their retinue of prospects and functional applications. These applications have been extensive in areas such as nutraceutical, pharmacological, cosmeceutical, functional food, insecticides and herbicides. The prospects of EPS include antithrombotic, anticoagulant, anticancer, immunomodulation and bioflocculants (Nwodo et al., 2012).

Bacterial based biopesticides are widely used in agricultural sector. Pseudomonas sp. synthesized several inhibitory compounds have broad spectrum antagonistic activity on plant pathogens (Cartwright et al., 2007). The genus Pseudomonas contains a large group of biocontrol strains and their ability to produce various active compounds was reported previously. The metabolites such as 2, 4-diacetylphloroglucinol, phenazine-1carboxylic acid and pyrrolnitrin [3-chloro-4-(2'-nitro3 'chlorophenyl)-pyrrole], as well as the complex, macrocyclic lactone are actively involved in biocontrol (Ligon et al., 2000).

Pseudomonas sp. BRG100 inhibits the growth of certain agricultural pests and is a potentially useful biopesticide for weeds and plant diseases. In agricultural practice, the widely used microbial pesticides are strains and subspecies of $B$. thuringiensis, commonly known as $B t$ (Chattopadhyay et al., 2004). It has been frequently used to control pests important in forestry, medicine and agriculture (Mazid and Kalita, 2011).

Many commercial biopesticides were available from Bacillus species such as $B$. pumilus, $B$. amyloliquefaciens, B. subtilis and B. licheniformis as biofungicides in the market (Kumar et al., 2008). Many species of Pseudomonas are also widely used for preparing biopesticides that include $P$. aeruginosa, $P$. fluorescence, $P$. syringae and $P$. aureofaciens (Kloepper et al., 2004). In spite of the various types of extra cellular polysaccharides which are commercially available, researchers are continuing to search novel polysaccharides with improved characters to meet the demand of the various industries. Most of the studies focused on the isolation of EPS from the bacteria and fungi for various applications. However, few studies on EPS from the waste water have been studied. Research work has been carried out to optimize the process conditions to enhance the production of EPS in submerged fermentation and few studies were carried out to explore the characteristic features of EPS. Considering these points, the present study was carried out to use EPS from $P$. aeruginosa $\mathrm{B} 01$ as a biopesticide.

\section{Materials and Methods}

\section{Isolation of bacterial isolate}

The wastewater samples were collected from Nagercoil Municipal area, Kanniyakumari District, Tamilnadu. The samples were serially diluted and plated on nutrient agar plates [(in g/l), (peptic digest of animal tissue, 5.0; beef extract, 1.5; yeast extract, 1.5; sodium chloride, 5.0; and agar, 15)]. All plates were incubated at $37{ }^{\circ} \mathrm{C}$ for $48 \mathrm{~h}$. The potent EPS producing isolate was retained by observing for good mucoid colony morphology (Fusconi and Godinho, 2002).

\section{Morphological, biochemical ad 16S rDNA sequencing of the potent EPS producing bacterial isolate}

Based on the morphological and biochemical tests the bacterial isolates were identified. The bacterial isolate which showed potent larvicidal activity was further subjected for $16 \mathrm{~S}$ rDNA sequencing. The universal primer was used to amplify the $16 \mathrm{~S}$ rDNA. The primers used were P1: 5'-AGAGTTTGATCMTGGCTAG-3' (forward) and P2: 5'-ACGGGCGGTGTGTRC-3' (reverse) (Rajiniemon et al., 2015). The DNA was amplified by using a Thermal Cycler Machine and DNA polymerase (Sigma-Aldrich, USA). The amplified PCR product was purified by standard method and sequenced. Sequence comparison with databases was performed using BLAST through the NCBI server (Altschul et al., 1997). The sequence was submitted to the GenBank database and an accession number was assigned.

\section{Inoculum preparation}

A loopful culture of $P$. aeruginosa B01 was inoculated into the nutrient broth medium composed of $(\mathrm{g} / \mathrm{l})$ peptone digest of animal tissue 5.0, sodium chloride 5.0, beef extract 1.5 , and yeast extract 1.5 . The medium $\mathrm{pH}$ was adjusted to 7.0 with $1 \mathrm{~N} \mathrm{HCl} / \mathrm{NaOH}$. The Erlenmeyer flask was incubated at $37{ }^{\circ} \mathrm{C}$ for $18 \mathrm{~h}$ in an orbital shaker at $150 \mathrm{rpm}$. It was stored at $2-8{ }^{\circ} \mathrm{C}$ and used as the inoculums for optimization studies. 
Effect of fermentation period on the growth and EPS production

About $0.5 \mathrm{ml}$ of inoculum was introduced into a $250-\mathrm{ml}$ Erlenmeyer flask containing basal medium consists of $(\mathrm{g} / \mathrm{l})$ : glucose- $0.5 \mathrm{~g}$; yeast extract- $0.1 \mathrm{~g}$; peptone- $0.25 \mathrm{~g}$; $\mathrm{KH}_{2} \mathrm{PO}_{4}-0.05 \mathrm{~g} ; \mathrm{MgSO}_{4}-0.01 \mathrm{~g}$ and $\mathrm{NaCl}-1.0 \mathrm{~g}$. The culture was incubated at $37{ }^{\circ} \mathrm{C}$ in an orbital shaker at 150 rpm for 8 days. At every $24 \mathrm{~h}, 10 \mathrm{ml}$ culture was withdrawn and the contents were centrifuged at 10,000 $\mathrm{rpm}$ for $15 \mathrm{~min}$ at $4{ }^{\circ} \mathrm{C}$. The cell free extract was subjected to ice cold ethanol and EPS content was assayed.

\section{Effect of carbon sources on EPS production}

The effect of carbon sources on EPS production was studied by supplementing various carbon sources such as glucose, lactose, maltose, fructose, sucrose, trehalose, and galactose at $1 \%(\mathrm{w} / \mathrm{v})$ level each in the basal medium inoculated with $500 \mu \mathrm{l}$ of bacterial strain. After 3 days of incubation, the cells were harvested. The culture supernatant was precipitated with ethanol and EPS content was assayed.

\section{Effect of nitrogen sources on EPS production}

The effect of nitrogen sources on EPS production was studied by supplementing various nitrogen sources such as beef extract, yeast extract, peptone, casein, skimmed milk, urea, and ammonium sulphate at $1 \%$ (w/v) level each in the basal medium inoculated with $500 \mu 1$ inoculum. After 3 days of incubation, the culture was centrifuged at $10,000 \mathrm{rpm}$ for $10 \mathrm{~min}$. The culture supernatant was precipitated with ethanol and EPS content was assayed.

\section{Effect of carbon - nitrogen ratio on EPS production}

To find out the suitable carbon, nitrogen ratio on EPS production, $P$. aeruginosa B01 was cultured in the medium with $20 \mathrm{~g} / \mathrm{l}$ glucose as carbon source adjusting the ratio of nitrogen source $(\mathrm{g} / \mathrm{l}) 5,10,15,20,25$, and $30 \%$ respectively. After 3 days of incubation, the cells were harvested. The culture supernatant was precipitated with ethanol and EPS content was assayed.

\section{Effect of ions on EPS production}

The ionic sources on EPS production was studied by supplementing metalic ions such as $\mathrm{Mg}^{2+}, \mathrm{Mn}^{2+}, \mathrm{Ba}^{2+}$,
$\mathrm{Cu}^{2+}, \mathrm{Ca}^{2+}, \mathrm{Zn}^{2+}$, and $\mathrm{Hg}^{2+}$ at $0.1 \%$ (w/w) level each in the basal medium inoculated with $500 \mu \mathrm{l}$ inoculum. After 3 days of incubation, the cells were harvested. The culture supernatant was precipitated with ethanol and EPS content was assayed.

\section{Effect of pH on EPS production}

Effect of $\mathrm{pH}$ on EPS production by $P$. aeruginosa was studied by adjusting into various $\mathrm{pH}$ such as 5.0, 5.5, 6.0, 6.5, 7.0, 7.5, and 8.0 using $1 \mathrm{~N} \mathrm{HCl} / \mathrm{NaOH}$. In the basal medium with various $\mathrm{pH}, 500 \mu \mathrm{l}$ of inoculum was introduced into an Erlenmeyer flask. Further, these flasks were incubated at $37{ }^{\circ} \mathrm{C}$ for 3 days. After 3 days of incubation, the cells were harvested. The culture supernatant was precipitated with ethanol and EPS content was assayed.

\section{Effect of temperature on EPS production}

Effect of temperature on EPS production was studied by inoculating the basal medium at various temperatures over a period of $8 \mathrm{~d}$. The temperatures maintained were $20,25,30,35,40,45$, and $50{ }^{\circ} \mathrm{C}$. In the basal medium incubated at various temperatures $500 \mu \mathrm{l}$ of inoculums was inoculated. After 3 days of incubation, the cells were harvested. The culture supernatant was precipitated with ethanol and EPS content was assayed.

Determination of EPS by phenol-sulphuric acid method

The EPS yield was measured by using phenol-sulphuric acid method (Chen et al., 2004). The amount of extracellular polysaccharide produced was calculated using an equivalent amount of glucose as the standard (Torino et al., 2001).

\section{Fractionation of EPS by various solvents}

For the extraction of EPSs, the crude EPS was mixed with the solvents such as chloroform, acetone, ethyl acetate, ethanol and methanol were used individually to precipitate the EPS. The pellet was removed and respective solvent was added (1:2 and 1:3 ratio) to the culture supernatant. It was stored at $4{ }^{\circ} \mathrm{C}$ for $24 \mathrm{~h}$ and the precipitates were separated. The precipitates were washed three times with double distilled water and were dialyzed against double distilled water using a dialysis membrane with an exclusion limit of $15 \mathrm{kDa}$. EPS precipitates were finally dried in a hot air oven $(40 \pm 2$ 
${ }^{\circ} \mathrm{C}$ ) to get a constant weight. The EPSs in the solid form were stored in airtight container at $4{ }^{\circ} \mathrm{C}$ for further analysis.

\section{Thin Layer Chromatography (TLC)}

The purified EPS was further loaded on TLC. The sample was placed on pre-coated silica gel (Merck, Bangalore) using benzene, acetic acid and methanol $(10: 10: 30)$ as the mobile phase and iodine crystal was used to develop the spots.

The spots were scraped and equal volume of double distilled water was added. This sample was further vortexed for $10 \mathrm{~min}$ and centrifuged at $10000 \mathrm{rpm}$ for 20 min. This sample was further used for characterization studies.

\section{Evaluation of antibacterial activity of EPS against selected pathogens}

\section{Test microorganisms}

For the antimicrobial activity studies, the bacteria such as Escherichia coli (MTCC 584), Klebsiella pneumoniae (MTCC 9544), Proteus vulgaris (MTCC 744), Enterobacter sp., (MTCC 11819) and Staphylococcus aureus (MTCC 9886) were used. These microorganisms were grown for $18 \mathrm{~h}$ at $37^{\circ} \mathrm{C}$ in nutrient broth medium $[(\mathrm{g} / \mathrm{l})$ peptic digest of animal tissue, 5.0; beef extract, 1.5; yeast extract, 1.5 and sodium chloride, 5.0] and used for antibacterial activity studies.

\section{Antimicrobial activity of EPS}

The EPS obtained from five different solvent precipitation was loaded on Mueller - Hinton agar plates and swabbed with pathogenic bacteria such as Escherichia coli (MTCC 584), Klebsiella pneumoniae (MTCC 9544), Proteus vulgaris (MTCC 744), Enterobacter sp., (MTCC 11819) and Staphylococcus aureus (MTCC 9886). The MHA medium was poured into the Petriplate and after solidification the inoculum was spread on the solid plates with sterile swab moistened with the bacterial suspension. Antibacterial activity of EPS was determined by well diffusion method on Mueller Hinton Agar (MHA) medium. The antibacterial substance loaded into the well prevents growth of bacteria in areas where active concentration is reached.

\section{Elucidation of insecticidal activity of EPS}

The mosquito larvae were collected from the stagnant waste water. Collected larvae were distributed in plastic containers. Toxicity assay was carried out by applying $1.0-5.0 \mathrm{mg}$ of EPS to the larvae. The experiment was continued upto $96 \mathrm{~h}$ and the mortality of the larvae was registered.

\section{Results and Discussion}

The EPS from Pseudomonas sp. showed potent activity against mosquito larvae ( $100 \%$ mortality). Hence, this organism was selected for further studies. This result was in accordance with the observations made previously with other Pseudomonas sp. It was previously reported that the metabolites produced by Pseudomonas sp. have insecticidal activity (Grundmann et al., 2012). The secondary metabolites produced by bacteria such as Photorhabdus sp. and Pseudomonas sp. are active against variety of insects as well as against microbial pathogens of plants and animals (Seo et al., 2012). In the present study, the potent EPS producing Pseudomonas sp. was subjected to $16 \mathrm{~S}$ rDNA sequencing. The BLAST analysis of the 16S rRNA sequence of Pseudomonas sp. has 95\% sequence similarity with Pseudomonas sp. in the NCBI database. The accession number of isolated strain submitted to genbank (KX 986759).

Incubation time is an essential factor determining the enhancement of EPS synthesis in the culture medium. As EPS is highly synthesized during late exponential growth phase or in the stationary phase, decrease in incubation time may lower the production. Higher incubation time might affect the yield due to the production of certain enzymes by the bacteria. As shown in figure 1, the bacterial growth was maximum after $48 \mathrm{~h}$ of incubation at $37{ }^{\circ} \mathrm{C}$, however growth decreased thereafter. EPS production was found to be high after $72 \mathrm{~h}$ of incubation.

These results indicated that the production of EPS occurred in the stationary phase of the organism. The present finding was similar to that of previous studies. Previously, in Staphylococcus epidermidis and $P$. aeruginosa, EPS production was found to be high during the early stationary phase and late logarithmic phase of microbial growth (Evan et al., 1994). Therefore, following optimization steps, this organism was cultured for $72 \mathrm{~h}$ to enhance the EPS production. 
Medium optimization helps to enhance the growth of organism and maximum EPS production. Optimization of EPS production was carried out previously to increase the EPS production from Pseudomonas sp., and Rhizobium sp. (Breedveld et al., 1993).

Table.1 Evaluation of larvicidal activity of EPS from the selected bacterial isolates

\begin{tabular}{|c|c|c|c|}
\hline \multirow[t]{2}{*}{ Bacteria } & \multicolumn{3}{|c|}{ Mortality (\%) } \\
\hline & $1 \mathrm{mg}$ EPS & $2 \mathrm{mg}$ EPS & $5 \mathrm{mg}$ EPs \\
\hline Bacillus sp. & $17 \pm 1.0$ & $21 \pm 1.8$ & $39 \pm 2.1$ \\
\hline Escherichia coli & $3.6 \pm 0.5$ & $5.8 \pm 1.2$ & $17.3 \pm 1.6$ \\
\hline Proteus sp. & $2.3 \pm 0.3$ & $7.3 \pm 0.55$ & $49.2 \pm 1.6$ \\
\hline Klebsella sp. & $48 \pm 3.8$ & $63 \pm 3.5$ & $93.3 \pm 2.9$ \\
\hline $\begin{array}{l}\text { Pseudomonas } \\
\text { aeruginosa }\end{array}$ & $100 \pm 1.2$ & $100 \pm 0.5$ & $100 \pm 0.25$ \\
\hline $\begin{array}{l}\text { Salmonella } \\
\text { typhimurium }\end{array}$ & $3 \pm 0.06$ & $4.9 \pm 0.09$ & $16.4 \pm 1.1$ \\
\hline $\begin{array}{l}\text { Staphylococcus } \\
\text { aureus }\end{array}$ & $47 \pm 0.09$ & $58.3 \pm 5.2$ & $96.8 \pm 2.7$ \\
\hline Bacillus cereus & 0 & 0 & $3.5 \pm 1.0$ \\
\hline Bacillus subtilis & $78.3 \pm 4.8$ & $89.1 \pm 1.0$ & $98.3 \pm 0.5$ \\
\hline Bacillus sp. & $84 \pm 3.3$ & $92 \pm 3.1$ & $93 \pm 0.25$ \\
\hline
\end{tabular}

Fig.1 Bacterial growth and EPS production at various incubation time in submerged fermentation

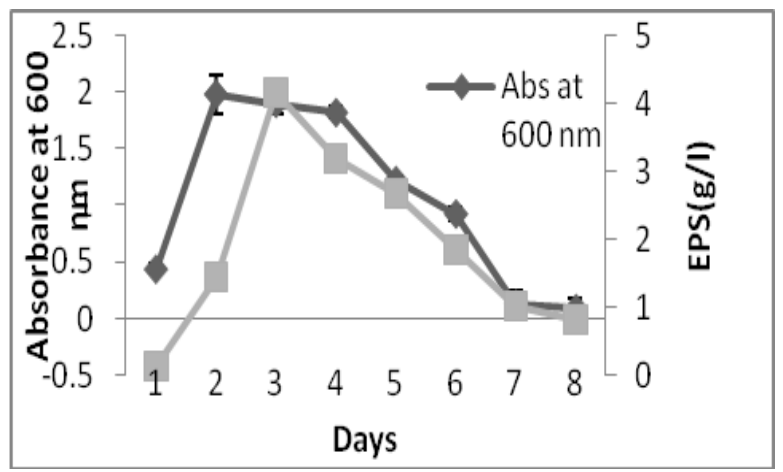

Fig.2a Effect of carbon sources on EPS production by $P$. aeruginosa B01

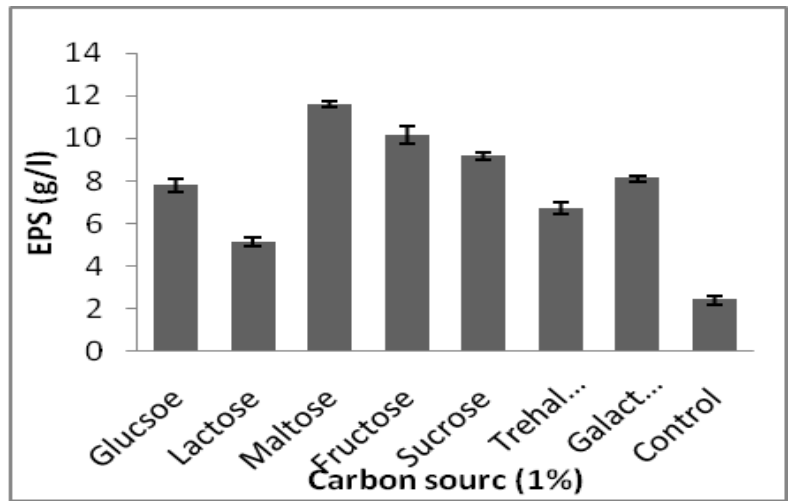


Fig.2b Effect of nitrogen sources on EPS production by P. aeruginosa B01

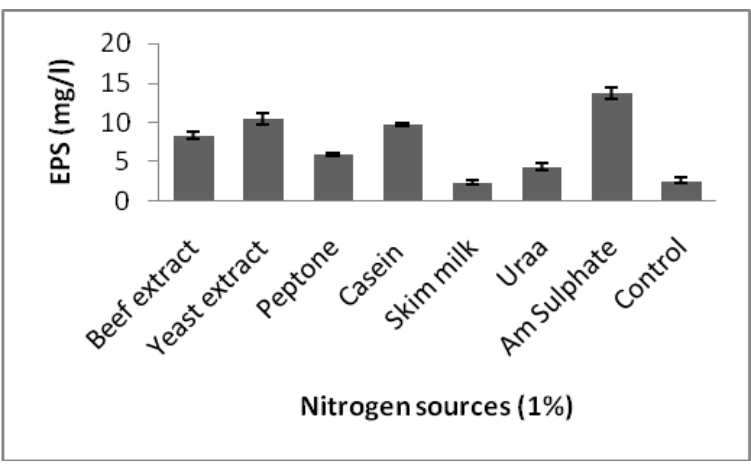

Fig.2c Effect of carbon and nitrogen ratio on EPS production by P. aeruginosa B01

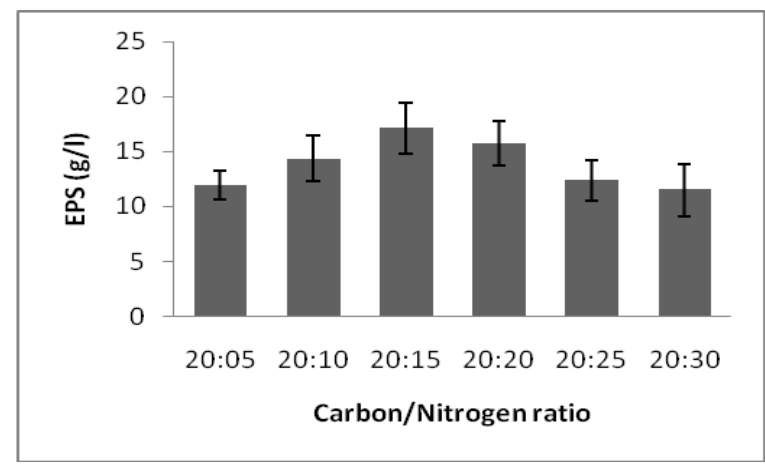

Fig.2d Effect of divalent ions on EPS production by $P$. aeruginosa B01

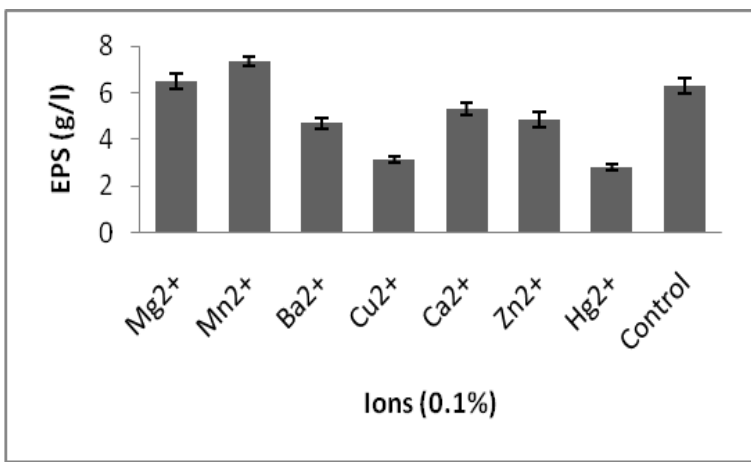

Fig.3a Effect of $\mathrm{pH}$ on EPS production by P. aeruginosa $\mathrm{B} 01$

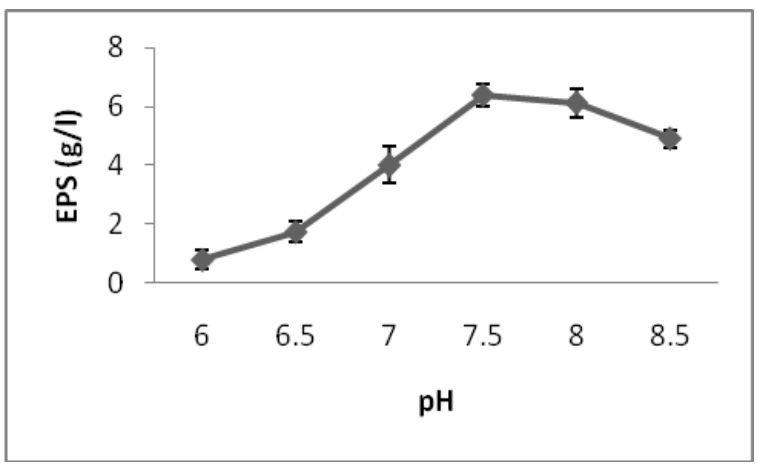


Fig.3b Effect of temperature on EPS production by P. aeruginosa B01

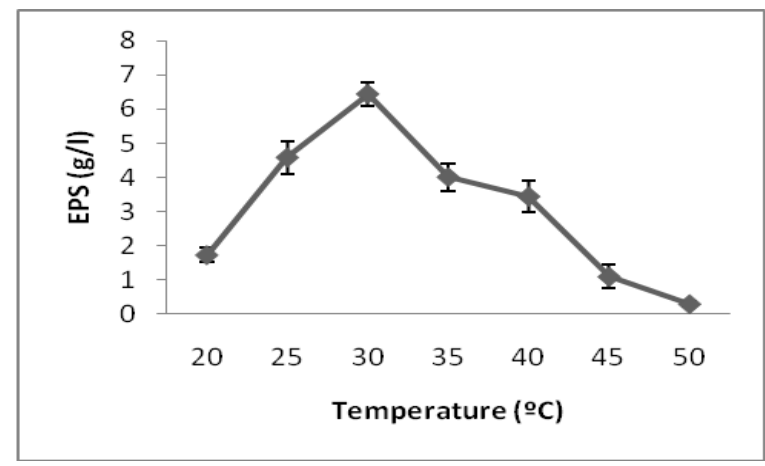

Fig.4 Precipitation of EPS using various solvent

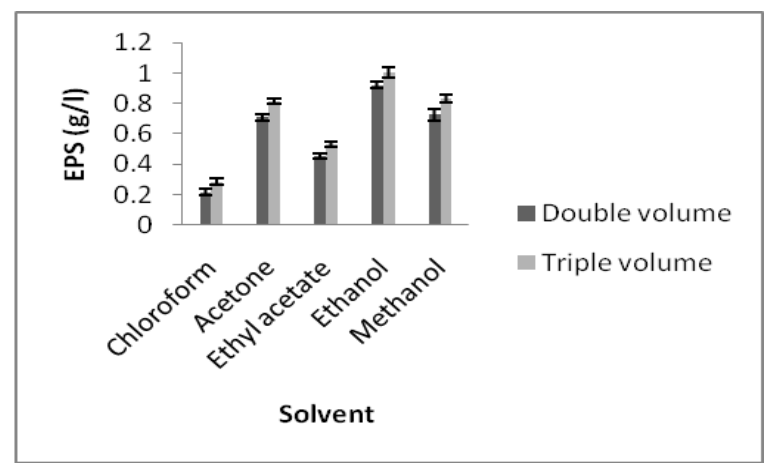

Fig.5 Antibacterial activity of EPS against E. coli (MTCC 584) (a); K. pneumoniae (MTCC 9544) (b); P. vulgaris (MTCC 744) (c); Enterobacter sp., (MTCC 11819) (d) and S. aureus (MTCC 9886) (e). EPS was precipitated with solvents such as chloroform, acetone, ethyl acetate, ethanol, methanol and loaded into the wells 1, 2, 3, 4 and 5, respectively

(a)

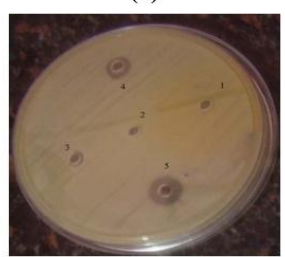

(c)

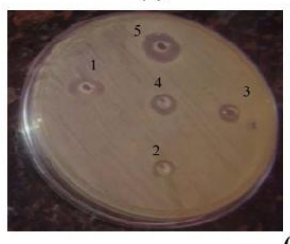

(b)

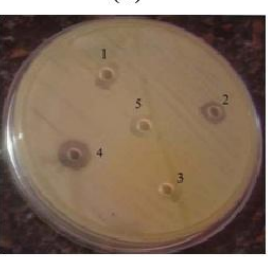

(d)

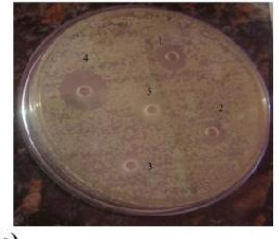

(e)

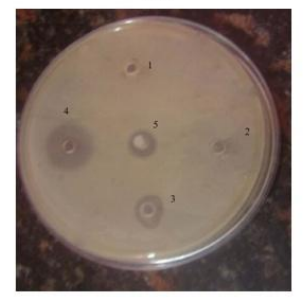


Fig.6 Thin Layer Chromatography of EPS from P. aeruginosa B01. The Rf value of EPS was found to be 0.83

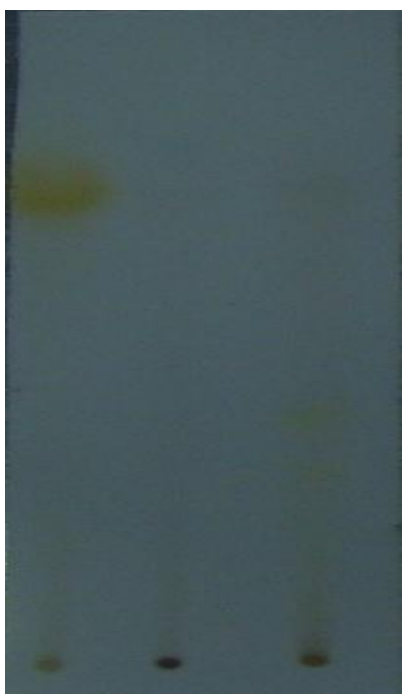

The EPS production by microbial strains mainly depends on the availability of nutrients in the culture medium. Various studies were carried out to elucidate the effects of different carbon substrates on EPS production previously. In the present study, EPS production was found to be high in the medium containing maltose as the carbon source (11.61 $\pm 0.138 \mathrm{~g} / \mathrm{l})$ (Fig. 2a). Similarly, in Cordyceps jiangxiensis, EPS production was found to be high in the medium containing maltose (Xiao et al., 2004).

In the present study, ammonium sulphate was used as the nitrogen source for bacterial growth and it significantly influenced on EPS production (13.71 $\pm 0.728 \mathrm{~g} / \mathrm{l}$ ) (Fig. $2 b$ ). This result was in accordance the observations made previously with many other bacterial species. It was earlier reported that the bacteria utilize ammonium salts as their sole source of nitrogen for their growth and EPS production (Czaczy and Wojciechow, 2003). It was also reported that under limited ammonium salts availability in the culture medium, more than $50 \%$ of the glucose was converted into EPS in the strains of Escherichia spp. (Lee et al., 1999). In the present study EPS production was maximum in the medium containing maltose and ammonium sulphate at the rate of 20:15 (Fig. 2c). The effect of various metal ions was studied and $\mathrm{Mn}^{2+}$ showed significant effect on EPS production $(7.34 \pm 0.19$ g/l) (Fig. 2d). This result was in accordance the observations made with Pseudomonas elodea. In $P$. elodea, EPS production was found to be maximum when this organism was cultured in the culture medium containing $\mathrm{Mn}^{2+}(6.25 \pm 0.1 \mathrm{~g} / \mathrm{l})$ (Dlamini and Peiris, 1997). The ions influence the catalytic activities of enzyme involved in microbial growth and EPS production. It was previously reported that the ions such as $\mathrm{Mn}^{2+}, \mathrm{Ca}^{2+}, \mathrm{Co}^{2+}, \mathrm{Fe}^{2+}$ and $\mathrm{K}^{+}$favour the growth and production of EPS (Petry et al., 2000).

The $\mathrm{pH}$ value of the culture medium might also be a one of the significant factors for the production of EPS by $P$. aeruginosa. In the present study, $P$. aeruginosa grown and produced EPS at range of $\mathrm{pH}$ values. In any microbial fermentation process, $\mathrm{pH}$ is one of a critical factor, because medium $\mathrm{pH}$ directly influences the physiology of a microorganism by affecting nutrient solubility and uptake, cell membrane morphology, EPS activity and product formation (Bajaj et al., 2009). In this study, EPS production was found to be high at $\mathrm{pH} 7.5$ $(6.38 \pm 0.381 \mathrm{~g} / \mathrm{l})$ and this was found to be optimum (Fig. 3a). Generally, the $\mathrm{pH}$ of the culture medium induces morphologically changes of the bacterial cells. Lee et al., (1999) reported that the optimal $\mathrm{pH}$ value for the EPS production ranged between 5.5 and 6.5 for most of the bacterial species. Shu and Lung (2004) reported the EPS production of Antodia spp., and it was found to be high in the culture medium containing $\mathrm{pH}$ value of 5.0. In P. polymyxa EJS-3, the maximum production of EPS was found at $\mathrm{pH} 8.0$ (Liu, 2009).

In bioprocess, incubation temperature is one of the critical factors which influence on EPS production. In this study, EPS production was found to be high when the organism was incubated at $30{ }^{\circ} \mathrm{C}(6.43 \pm 0.34 \mathrm{~g} / \mathrm{l})$ (Fig. 3b). It was previously reported that the temperature plays critically on the growth and EPS production. Kandler and Weiss (1986) reported that the optimum 
temperature for EPS production was found within the optimum growth the bacterial strain $\left(37^{\circ} \mathrm{C}\right.$ to $\left.45^{\circ} \mathrm{C}\right)$. The search of new classes of antibiotics is an urgent need because of increased incidence of multiple resistances among pathogenic microorganisms to drug that is currently in clinical use. Mehta et al. (2014) characterized novel EPS from the osmotolerant marine strain of Alteromonas macleodii for various applications including biomineralization of silver. The antimicrobial EPS was also reported earlier from Pseudomonas aeruginosa B1 and B2 (Onbasli and Aslim, 2008). In the present study the EPS was precipitated by five different solvent (chloroform, acetone, ethyl acetate, ethanol and methanol). Among the solvent, ethanol precipitated EPS showed considerable amount than other solvent (Fig. 4) The precipitates were subjected to evaluate its biological activity against the human pathogens such as Escherichia coli (MTCC 584), Klebsiella pneumoniae (MTCC 9544), Proteus vulgaris (MTCC 744), Enterobacter sp., (MTCC 11819) and Staphylococcus aureus (MTCC 9886). The solvent precipitated EPS showed antibacterial activity against most of the selected pathogens. The methanol extract of EPS was highly active against Enterobacter sp., (MTCC 11819) and K. pneumoniae (MTCC 9544). The ethanol extract of EPS was highly effective against the pathogens such as E. coli (MTCC 584), P. vulgaris (MTCC 744), and S. aureus (MTCC 9886) (Fig. 5). Ethanol precipitated EPS fraction was loaded on Thin Layer Chromatography and it was separated (Fig. 6). The ethanol precipitated EPS showed larvicidal activity. The EPS produced by $P$. aeruginosa B01 showed $100 \%$ larvicidal activity, followed by Bacillus sp. $(84 \pm 3.3 \%$ to $93 \pm 0.25 \%$ activity) (Table 1 ).

\section{References}

Altschul, S.F., Madden T.L., Schäffer A.A., Zhang J., Zhang Z., Miller W., et al. 1997. Gapped BLAST and PSI-BLAST: A new generation of protein database search programs. Nucleic Acids Res., 25: 3389-402.

Bajaj, I.B., Lele, S.S. and Singhal, R.S. 2009. A statistical approach to optimization of fermentative production of poly (gamma glutamic acid) from Bacillus licheniformis NCIM 2324. Bioresour. Technol., 100: 826-832.

Breedveld, M.W., Zevenhuizen, L.P.T.M., Canter Cremers, H.C.J. and Zehnder, A.J.B. 1993. Influence of growth conditions on production of capsular and extracellular polysaccharides by Rhizobium leguminosarum. Antonie Leeuwenhoek, 64: $1-8$.
Cartwright, D.K., Chilton, W.S., Benson D.M. 2007. Pyrrolnitrun and Phenazine production by Pseudomonas cepacia strain $5.5 \mathrm{~B}$, a biological agent of Rhizoctonia solani. Appl. Microbiol. Biotechnol., 53: 211-217.

Chattopadhyay, I., Biswas, K., Bandyopadhyay, U. Banerjee RK. 2004. Turmeric and curcumin: Biological actions and medicinal applications. Curr. Sci., 2004, 87:44-53.

Chen, D.X., Liu, J.W., Liu, Z.L., Wan, W.H., Fang, N., Xiao, Y., Qi, Y., Liang, Z.Q. 2004. Optimization of submerged culture requirements for the production of mycelial growth and exopolysaccharide by Cordyceps jiangxiensis JXPJ 0109. J. Appl. Microbiol., 96: 1105-1116.

Czaczy, K.K. and Wojciechow, S.K.A.K. 2003. Formation of bacterial biofilms - the essence of the matter and mechanisms of interactions. Biotechnologia, 3: 180-182.

Dlamini, A.M. and Peiris, P.S. 1997. Production of exopolysaccharide by Pseudomonas sp. ATCC 31461 (Pseudomonas elodea) using whey as fermentation substrate. Appl. Microbiol. Biotechnol., 47(1): 52-57.

Evan, S.E., Brown, M.R. and Gilber, T.P. 1994. Iron chelator, exopolysaccharide and protease production in staphylococcus epidermidis: a comparative study of the effects of specific growth rate in biofilm and planktonic culture. Microbiol., 140:153-161.

Flemming, H. and J. Wingender J. 2010. The biofilm matrix. Nat. Rev. Microbiol., 8: 623-633.

Fusconi, R. and Godinho, M.J.L. 2002. Screening for exopolysaccharide -producing bacteria from subtropical polluted groundwater. Braz. J. Biol., 62(2): 363-369.

Grundmann, F., Dill, V.A., Dowling, A., Thanwisai, E., Bode, N. 2012. Chantratita, Richard ffrenchConstant, and H.B. Bode: Identification and isolation of insecticidal oxazoles from Pseudomonas spp. Beilstein J. Org. Chem., 8: 749-752.

Kandler, O. and Weiss, N. 1986. Regular, non-sporing Gram-positive rods. Genus Lactobacillus. In: Sneath PHA, Mair NS, Sharpe ME, Holt JG (Eds) 1986. Bergey's Manual of Systematic Bacteriology, Williams and Wilkins, Baltimore, pp1209-1234.

Kloepper, J.W., Ryu, C.M. and. Zhang, S. 2004. Induced systemic resistance and promotion of plant by Bacillus spp. Phytopathology, 94: 1259-1266.

Kumar, S., Chandra, A. and Pandey, K.C. 2008. Bacillus thuringiensis (Bt) transgenic crop: an environment friendly insect-pest management strategy. $J$. Environ. Biol., 29: 641- 653. 
Lee, J.W., Yeomans, W.G., Allen, A.L., Deng, F., Gross, R.A. and Kaplan, D.L. 1999. Biosynthesis of novel exopolymers by Aureobasidium pullulans. Appl. Environ. Microbiol., 65: 5265-5271.

Ligon, J.M., Hill, D.S., Hammer, P.E., Torkewitz, N.R., Hefmann, D.K., Kempfy H.J., Van Pee. K.H. 2000. Natural products with antifungal activity from Pseudomonas biocontrol bacteria. Pest Manage. Sci., 56: 688-695.

Liu, J. 2009. Production, characterization and antioxidant activities in vitro of exopolysaccarides from endophytic bacterium Paenibacillus polymyxa EJS3. Carbohydr. Polym., 78: 275-280.

Mazid, S. and Kalita, J.C. 2011. A review on the use of biopesticides in insect pest management. Int. J. Sci. Adv. Technol., 1: 169-178.

Mehta, A., Sidhu, C., Pinnaka, A.K. and Choudhury A. 2014. Extracellular polysaccharide production by a novel osmotolerant marine strain of Alteromonas macleodii and its application towards biomineralization of silver. PLOS ONE 2014, 9:98 798.

Nwodo, U.U., Green, E, and Okoh, A.I. 2012. Bacterial exopolysaccharides: functionality and prospects. Int. J. Mol. Sci., 13: 14002-14015.

Onbasli D. and Aslim. 2008. Determination of antimicrobial activity and production of some metabolites by Pseudomonas aeruginosa B1 and B2 in sugar beet molasses. African J. Biotechnol., 7(24): 4614-4619.

Petry, S., Furlan, S., Crepeau, M.J., Cerning, J. and Desmazeaud, M. 2000. Factors Affecting Exocellular Polysaccharide Production by Lactobacillus delbrueckii subsp. bulgaricus Grown in a Chemically Defined Medium. Appl. Environ. Microbiol., 66(8): 3427-3431.

\section{How to cite this article:}

Benit, N. and Stella Roslin, A. 2017. Production of Antibacterial and Larvicidal Extracellular Polysaccharide from Pseudomonas aeruginosa Strain b01 Isolated from Wastewater. Int.J.Curr.Res.Aca.Rev. 5(6), 6-15.

doi: https://doi.org/10.20546/ijcrar.2017.506.002
Rejiniemon, T.S., Hussain, R.R. and Rajamani, B. 2015. In-vitro functional properties of Lactobacillus plantarum isolated from fermented ragi malt. South Ind. J. Biol. Sci., 1(1): 15-23.

Seo, S., Lee, S., Hong, Y. and Kim, Y. 2012. Phospholipase A2 inhibitors synthesized by two entomopathogenic bacteria, Xenorhabdus nematophila and Photorhabdus temperata subsp. temperata. Appl. Environ. Microbiol., 78: 38163823.

Shu, C.H. and Lung, M.Y. 2004. Effect of $\mathrm{pH}$ on the production and molecular weight distribution of exopolysacharide by Antrodia camphorate in batch cultures. Process Biochem., 39: 931-942.

Sutherland I.W. 1977. Surface Carbohydrates of the Prokaryotic Cell; Academic Press, Vol. London.

Sutherland, I.W. 1985. Microbial extracellular polysaccharides and its applications in food industry. Ann. Rev. Microbiol., 1985, 39: 243-270.

Torino, M.I., Taranto, M.P., Sesma, F., and Font de Valdez, G. 2001. Heterofermentative pattern and exopolysaccharide production by Lactobacillus helveticus 15807 in response to environmental $\mathrm{pH}$. J. Appl. Microbiol., 91: 846-852.

Tsuneda, S., S. Park, H. Hayashi, J. Jung and Hirate A. 2001. Enhancement of nitrifying biofilm formation using selected EPS produced by heterotrophic bacteria. Water Sci. Tech., 43(6): 197-204.

Vu, B., M. Chen, R. Crawford and Ivanova E. 2009. Bacterial extracellular polysaccharides involved in biofilm formation. Molecules, 14: 2535-2554.

Xiao, J.H., Chen, D.X., Liu, J.W. et al. 2004. Optimization of submerged culture requirements for the production of mycelial growth and exopolysaccharide by Cordyceps jiangxiensis JXPJ 0109. J. Appl. Microbiol., 96: 1105-1116. 